\title{
Dealing with Student Misbehavior in Urban Settings
}

\author{
Madalina Tanase \\ College of Education and Human Services \\ Department of Teaching, Learning, and Curriculum \\ 1 UNF Drive, Jacksonville, FL, 32224 USA \\ Email: madalina tanase@unf.edu
}

\section{Abstract}

Issues with classroom management are the main reason teachers quit the profession. Effective classroom management starts with the teacher, as the ability to manage the environment is critical in designing productive environments. Utilizing effective strategies is a challenging task due to the disconnect between what the teacher and the students consider inappropriate behavior. In this qualitative study, the researcher conducted interviews with twenty-two novice teachers in urban schools in the United States while discussing some classroom management strategies they used in their secondary mathematics and science classrooms. Results show that the participants successfully used nonverbal and verbal interventions to deal with minor behaviors.
\end{abstract}

Keywords: urban setting, classroom management, verbal interventions, non-verbal interventions

DOI: $10.7176 / \mathrm{JEP} / 11-7-07$

Publication date:March $31^{\text {st }} 2020$

\section{Introduction and Review of Literature}

\subsection{Classroom Management: A Perpetual Issue in the Schools}

Disruptive behaviors continue to be problematic in US classrooms (Farah 2017; Reinke et al. 2014). Such behaviors may include clowning, avoidance of work, inappropriate device usage, chit chats, unauthorized movement, disrespect to adults and peers, etc. (Kowalski 2003; Ripp 2013; Sun and Shek 2012). The impact of such behaviors on the overall climate of the classroom is negative: students may become distracted and disengaged, which in turn, may lead to an overall low productivity (Farah 2017). Novice teachers identify classroom management issues as a top complaint (Hertzog 2002; Meister and Melnick, 2003), resulting in a large number of them leaving the profession (Ingersoll 2002).

In general, teachers in urban schools face more challenges than their counterparts who teach in suburban and rural schools due to cultural and social factors. According to Brown (2003), "Classroom management in urban schools is more difficult than in rural or suburban schools because gaining students' cooperation while ensuring their learning involves addressing students' cultural, ethnic, social, identity development, language, and safety needs, as well as their academic growth" (278). Moreover, Ullucci (2009) argued that "when we overlap issues of management with urban schooling further complications arise" (14).

Some researchers, such as Freiberg, Huzinec, and Templeton (2009), Lewis et al. (2004), and Skiba et al. (2016) have documented the connection between classroom management and student achievement. According to Skiba et al. (2016), "Maintaining a positive and organized classroom setting free from disruption is critical to providing an instructional environment conducive to teaching and learning" (12). Similarly, Oliver (2007) argued that an organized classroom can lead to positive outcomes, "The ability of teachers to organize classrooms and manage the behavior of their students is critical to achieving positive educational outcomes" (4).

A teacher's ability to develop a positive classroom climate and to find ways to deescalate student behavior has important consequences for students (Skiba et al., 2016). Effective classroom management can reduce distractive behaviors (Hawkins et al. 1999). This is critical to the wellbeing of teachers and students, and fundamental to ensuring safe and productive learning environments. Conversely, the teacher's inability to manage classroom behavior often results in increased misbehavior, as well as the low achievement of at-risk students (Donovan and Cross 2002; Harrell et al. 2004).

However, utilizing effective strategies is not easy, due to the disconnect between what the teacher and the students regard as appropriate behavior (Boice 1996). When teachers correct undesirable actions, many students believe they did nothing wrong in the first place. This can create hostility and lead to even bigger escalations. When negative interactions escalate beyond the ability of the teacher to handle them in the classroom, teachers send students to the administrative office (Skiba et al. 2016). In turn, this may have negative effects, as students believe teachers are incapable of managing their classrooms, and therefore lose confidence in the teacher's ability (Teaching Tolerance 2016).

It is preferable to prevent misbehavior than to correct it. Establishing classroom guidelines in the beginning of the semester and discussing them with the students are two of the most significant preventive techniques, as properly designed guidelines "provide students with clear expectations and well-defined norms, which in turn will give them feelings of safety, security, and direction" (Levin and Nolan 2014, 155). However, despite the best 
preventive measures, "all teachers eventually have to deal with problem behaviors in the classroom" (Weinstein, Curran, and Tomlinson-Clarke 2003, 274). The essential question is therefore what constitutes effective strategies. In order to offer more in-depth knowledge about effective classroom management, I investigated some strategies secondary mathematics and science teachers used effectively to deescalate behaviors. But before sharing some of the findings of the current study, it is important to acknowledge previous research on effective strategies.

\subsection{Effective Non-Verbal Interventions}

Whenever possible, teachers should use non-verbal cues. Eye contact (i.e. "the look"), body language, proximity, touch and signal interference, and quiet attention getters are considered some of the most effective nonverbal communication tools. Using proximity can help students understand that the teacher wants to stop the behavior in the least intrusive way; the teacher's presence may nudge the student to return to the appropriate behavior (Nasey 2012). Similarly, a gentle tap on a desk or student's shoulder, or "catching a student's eye and circulating throughout the classroom all have the power to help students refocus and stay on task" (Teaching Tolerance 2016, 11). Moreover, non-threatening body language conveys the message that the teacher is in control of the class, but also that he/she cares about the students (Teaching Tolerance 2016).

With practice, teachers can master the look. With one glance, teachers can stop misbehavior, redirect students, or indicate approval or disapproval. Some develop "eyes at the back of their heads," constantly surprising their students. Pres (2017) stated that teachers "use the stare because it works, it costs us nothing in power, time, or energy" (1). However, since eye contact and proximity may become cultural issues, Galanti (2008) urged teachers to use their wisdom when looking students in the eye or placing themselves too close to a student. For example, in Eastern Asian cultures, making eye contact with a person of a dominant status is disrespectful; however, in the Western culture, avoiding eye contact may be seen as suspicious. In addition, low-contact cultures (i.e., US, England, Japan) value personal space, so being too close to someone is frowned upon. On the contrary, highcontact cultures (i.e. Latin American and Middle Eastern culture) view proximity in a positive light (Axtell 1997). Lastly, the quiet attention getters may also redirect student behavior. An example of this strategy is the "give me five" strategy. According to Hollie (2012), the teacher raises a hand, and the students raise their hands back to the teacher and give a high five in the air.

\subsection{Effective Verbal Interventions}

Early intervention is key to preventing problem behaviors from escalating into serious incidents (Skiba et al. 2016). When non-verbal interventions fail, teachers should employ verbal interventions. These include, among others, the use of humor, reinforcement of positive behavior, attention getters, and the touch-and-go strategy. A very effective intervention in addressing misbehavior is the use of humor. Teachers can use humor in order to break the ice with difficult students and motivate them to respond in a positive way both socially and academically. The use of humor enables teachers to develop relationships with the students, as the students "feel comfortable talking to them about a variety of issues_-both academic and personal" (Rose and Parker 2014, 3). Teachers who use humor in their classrooms encourage their students to laugh and use humor themselves. However, Levin and Nolan (2014) urged teachers to be careful not to turn humor into sarcasm, distinguishing between these two, "Used as a verbal intervention, humor is directed at or makes fun of the teacher or the situation, whereas sarcasm is directed at or makes fun of the student" (223).

In addition, attention getters may serve as a quick reminder of the classroom rules, or to refocus the unwarranted behavior. In order to be effective, attention getters need to be taught the first days of school. Such attention getters may include calls ("One-two-three, eyes on me!" "One-two eyes on you!"), and claps (the teacher claps first and then the students respond to the clap). Another example can be when the teacher stands in front of the room, providing students with brief oral directions in a voice that is louder than the students' voices. Instruction begins when most students pay attention (Grinder 2005).

At times, teachers may escalate small behaviors by dwelling on the issue, engaging in power struggles with the students, or publicly humiliating the students. The "touch-and-go" is a very effective strategy which allows the teacher to address the issue quickly and quietly and move on, "If a student is engaging in the behavior to seek attention, drawing focus away from the behavior will likely cause it to stop" (Teaching Tolerance 2016, 11).

Moreover, better results occur when teachers reinforce positive behavior, rather than punish misbehavior. Teachers can reinforce individual behavior or group behavior with both tangible rewards (i.e. prizes, privileges) and intangible rewards (i.e. praise). Praising good behavior is more effective when teachers are specific, saying, for example, "Good job finding your seat quickly," or "Thank you for sharing your crayons" (Teaching Tolerance 2016, 9). Praises may be public or private. When praising the students in public, teachers can either praise the group, or they can praise the individual. In the case of individual praises, the teacher should be aware of how the student will feel about public recognition; in some cases, private praises may work more effectively with individual students. 


\section{Methodology and Context of the Current Study}

The participants of this longitudinal study were twenty-two mathematics and science teachers who had been teaching for up to three years at the time this study was conducted. All participants graduated from an urban graduate teacher residency program from a mid-sized university in the southeastern United States. This was the only graduate teacher residency program at this university and in the city. I had previously taught all three cohorts as they were undergoing the program, and upon completion, I asked all former students to participate in the study; twenty-two agreed to participate. There were thirteen females and nine male participants of an age average of thirty. Thirteen participants were Caucasians, seven African-American, one Asian, and one Latina. Thirteen were mathematics teachers, and nine were science teachers. The participants belonged to three different cohorts of the graduate program: cohort one started teaching in the Fall 2016; cohort two started teaching in the Fall 2017; and cohort three started teaching in the Fall 2018.

The directors of the residency program, in collaboration with the school district, placed the participants in eight urban middle and high schools in the city where they graduated. According to The Center for Technology in Education (2018), urban schools generally have larger enrollments than suburban or rural schools, and they mostly serve low-income students. Behavior problems in the areas of absenteeism, classroom discipline, weapons possession, and student pregnancy are more common in urban schools. Moreover, $40 \%$ of students in urban locales attend high poverty schools, where more than $40 \%$ of students receive free or reduced lunches. On average, students in urban schools have lower achievement scores than their suburban peers.

The directors of the residency programs chose the 8 schools because they met the criteria of low-income, high-poverty schools, and they were situated in the poorest area of the city. The mean annual income of the neighborhoods where the participants taught was $\$ 25,971$, versus a national median income of $\$ 55,322$. All the schools were historically black, with a student population of over $90 \%$ African American, 1-3 \% Hispanic, and 2$4 \%$ Caucasian students. The most recent data found on the Florida Department of Education website indicated that the graduation rate for these schools in the year 2015-2016 was $75 \%$, while dropout rate was $3 \%$. Moreover, $70 \%$ of the students were low-income. The school district rated these schools with the grades of B (average) and C (below average). All the schools offered free and reduced lunches (Florida Department of Education n. d.).

To collect the data, I used the following two main instruments: a teacher interview and an observation packet. I developed and implemented the teacher interview, prompting the participants to answer seventeen open-ended classroom management questions. As this was a longitudinal study, I interviewed the teachers in cohort one in 2016 for the first time. In 2017, I returned to interview the teachers in cohorts one and two, and in 2018, I interviewed the teachers in all three cohorts.

The Mentor Observation Packet was developed by the School District where the research took place. In the first part, the participants answered eight pre-observation questions, which were geared towards their classroom management. The second and third parts of the packet contained information to be used during the observation. In the second part, a second researcher observed the whole class for twenty minutes, tallying the student engagement and teacher-to-student interactions. In the third part, the same researcher focused on one student for five seconds for a total of ten minutes, tallying the on-task/off-task behaviors. The second researcher conducted the classroom observations for all three cohorts, following the same schedule as the teacher interviews. Because we obtained more data from cohort one than from the other cohorts, for the current study I decided to only use the data collected in the first year of teaching for all participants for uniformity reasons.

\section{Results}

\subsection{Handling Minor Distractions in Secondary Urban Settings}

\subsubsection{Non-Verbal Interventions}

Whenever possible, the teachers used non-verbal interventions to regain students' attention. The most frequently used non-verbal interventions were proximity, the teacher look, and the touch and signal interference; among these, proximity was the most common. Its strength lies in its effectiveness to redirect misbehaviors without disrupting the class: "Proximity I think is the best because you can keep on teaching while walking around," Ethan stated, while Mitchell echoed, "Proximity is what I try to do first, otherwise I quietly tell them, go ahead and put your phone away." Stephen used proximity for those students who disliked teacher closeness, "For the ones that start acting up even more, I'm like, look I will go away but you need to do this, because I have to keep coming over here if you're not doing it. Then I'll walk away. So, start doing it, or I'm going to come back." On the other hand, Anna used proximity because of its element of surprise, "Proximity is the main one I like to use because I guess many of them don't think that I see what they're doing or notice what they're doing for some reason."

The "teacher look" was another commonly used non-verbal intervention. All teachers mastered the look. For example, Adam and Andrea stared at their students, "I'm really good at my stare eyes. Yes, we look each other in the eyes and they just get back to work. That is my go- to look right now," Adam said, while Andrea reflected, "If they are talking while I am talking...I will keep talking and just kind of stare in their direction and usually people are like, dude, she is staring at you." Greg and Ethan used the "you are in trouble look", "Because I'm a smiley 
person, I'm always smiling; if I'm not smiling, they know something's wrong," said Greg. Ethan chimed in, "I give specific students the look. When I say, clap one time or two times and some students are still talking, I even give them a little, "you are starting to cross the line look." Carmen's students recognized her teacher look, "I'll give them the teacher look. And they know." Chris's whole demeanor, on the other hand, communicated that he meant business, "The demeanor that I have in the classroom is very businesslike, it is like get in, sit down, get to work. I don't have time for that."

Other teachers used the touch and/or signal interferences to refocus their students. Dawn's touch interference was a tap on the desk to help her students focus, "I can tap their desk and bring them back to focus," while Ethan and Courtney used gentle taps on their students' shoulders, "Physical contact, a pat on the shoulder or something," Ethan reflected; "A little tap on the shoulders or something like non-verbals so they get the message but it doesn't call them out," Courtney added. Finally, Andrea used both a tap on the desk and a tap on the shoulder, "So if I am teaching and the student is putting his head down, I may just keep talking and just pat on their shoulder or tap on their desk." On the other hand, Greg used the signal interference to correct misbehavior, "I'll do this hand signal which is me flipping my hand to let them know to put their phone up. If I see a phone, I'll be like, put it up... so silent things."

3.1.2 Verbal Interventions

Whenever non-verbal interventions failed, teachers relied on verbal interventions to gain their students' attention. Some commonly used strategies were redirects, name dropping, warnings, attention getters, humor, the "hit and go," and reminders. A few teachers used humor to help correct student behavior. Humor was Mary's go-to strategy, "I typically go to humor first. I always like to make a situation much lighter than it has to be because these are emotional teens and it can go to one thousand with no time at all," while Ethan confessed that joking with his students was a preferred strategy, "If they are on their phone, you pretend to be interested, like scrolling on their phone. Obviously, you need a relationship to be able to touch their phone. That is me through, not everybody is a jokester."

Similarly, Alyssa's use of humor reflected her personality, "I like always adding in humor because that's just who I am as a person. Adding humor into it makes it a little bit less scary for them so it's not like, oh my gosh I'm in trouble; it's like, she's calling us out, I better stop doing this." On the other hand, Sally sang Disney songs to defuse situations, "I've used this a couple of times, like today actually they were being ridiculous and I was like let it go, let it go, and they were like oh, my gosh, she is singing and I'm like yes, let it go. It's OK."

Other teachers used attention getters. Ethan stated, "Another classroom management strategy I use is, clap if you can hear me, 3-2-1 everybody come back to me." Similarly, Greg got his students' attention before continuing to teach, "I'll count down for everyone. A lot of times I still won't have their attention so I'll be like, all right, we forgot what it means when I get to one. Let me count down from 5, 4, 3, 2, 1. If it takes more than two times, I'll ask one of the people who is ignoring me, hey, M., can you explain what it means when I get to one? Oh, it means we're quiet. All right, perfect! Thank you, M. Let me try again: 5, 4, 3, 2, 1. Making sure I have everyone's attention before I do anything really helps."

Most teachers used name-dropping to help refocus specific students. For example, Dawn mentioned a student by her name while looking at her, "I say her name and try to keep it moving," while Greg inserted his students' name into the discussion, "So it's like, the function of these molecules is, Adam, to make sure... I'll just namedrop and that gets their attention and they'll assess whatever they're doing and be like, oh, he doesn't want my phone out." Anna also used name-dropping successfully, "I'll say something and keep on moving, or include their name and what they are saying or ask them the question...most of the time they don't know the answer so I'll ask them why. And they will even tell you, because I wasn't paying attention, because I was talking, so I don't have dwell too much because then it takes time away."

Teachers also used redirects (i.e. short statements meant to refocus students), as well as reminders of expected behavior. For example, Andrea redirected her students with a broad statement, "I may look in her direction or I may not. If you have your phone on you, know I am talking to you. Put that phone away." Similarly, Courtney used quick redirects along with name-dropping, "If it's really minor that I have to call them out it's like eyes up here for like small stuff and so-and-so make sure you're paying attention. I like asking the question, what's the answer to these and they're like, hum... it's like, I will come back to you so then we go back." Sam explained how he used redirects in his class: "If I'm up here talking, I may just give a redirect like, eyes on me, or I'm losing you...I only have two more minutes. Or, we are going to talk for only 30 seconds, so listen."

Other teachers gave verbal warnings while preserving their students' dignity. For example, Stephen said, "Usually it's like, stop for just a second, we'll get to that in a minute and then I go back to what I'm doing. Or I'll just tell them cut it out, or I'll stand near them until they get uncomfortable. It doesn't work with some of them, it's the complete opposite, so I know to stay away from them."

Lastly, some teachers used the 'touch-and-go' technique effectively, by quickly addressing the behavior and continuing instruction. Tammy stated, "I just address it quickly and move on. If they're tapping the desk, I won't even look at them, I'll say whoever is tapping, please stop, and I just keep going." Luke liked this strategy because 
it preserved student dignity, "I'm not trying to belittle anybody and I'm not trying to make a scene. I tell them to turn around, keep moving, I don't even look at them. They know the rules. They will try to engage. If they try too many times, I will say, ok, I'm not going to tell you anymore, I'm just going to document it." This is how Mary summed up the benefit of this strategy, "You don't even give them any extra attention. You don't give them a stage in front of the whole class. They know what you expect out of them and they know that they are doing something that is outside of the expectations. So just a quick touch on their table, a quick tap on their phone or shoulder, and when they turn around and look... a quick smile, which means, I see you. And they will put it right away or they will get right back on task. Sometimes you have to do that a lot."

\subsection{Measuring the Effectiveness of One's Classroom Management}

Overall, the teachers in this study believed they were successful classroom managers if misbehaviors decreased over time and if, in turn, acceptable behaviors increased, "I know if my classroom management plan is effective if the negative behaviors in my classes are reduced and my positive behaviors increase over time," Stephen said, "Students improve if their previous behavior was negative," Greg echoed. On the other hand, Courtney and Anna mentioned having fewer disruptions in class. Courtney stated, "I know it is effective if I am able to teach my lesson with fewer disruptions and I can call the whole class back without losing too much instruction time." Anna agreed: "I know that my management plan is effective if I have fewer disruptions in class or I am able to redirect those distractions without any time lost in the lesson."

In the same vein, teachers talked about students being able to self-regulate as a measure of a successful classroom management. Stephen stated, "I know that my classroom management plan is effective particularly if students are reminding each other of what is required or pushing each other to get back on task," and Chris echoed, "Students may also take part in regulating themselves and others." Another measure of success was students' ability to work independently and collaboratively. Sally, Alyssa, and Mitchell reflected that their students were on task. Sally said, "My students are on task, working collaboratively and positively with each other. They are following my expectations, they are engaged," while Alyssa reflected, "If students are on task and engaging with the lesson, then I know it was effective." Mitchell added, "If my classroom management plan was effective, students will be focused and on-task for the majority of class."

Moreover, Chris and Irene also discussed the importance of student engagement, "Students will be engaged and motivated to learn," Chris said, while Irene commented, "All students would be able to discuss the content covered that day by questioning and peer support." Moreover, Greg added that his students felt comfortable in his class, "Students are laughing, smiling, participating (meaning they feel comfortable I the classroom)."

To triangulate the effectiveness of the classroom management plan, a second researcher conducted classroom observations with all the teachers. This researcher tallied the results in following two categories: student engagement and time on task. To account for student engagement, the researcher observed the whole classroom for a period of twenty minutes. The student engagement was recorded only for twelve participants in cohorts one and two. The researcher noted that forty-six disruptions, redirections or corrections took place during the twentyminute observation (an average of $5.5 \%$ ). The number of praises, both general and specific was higher, a total of eighty-seven (an average of $10 \%$ ). Moreover, the researcher observed on/off task behaviors for ten minutes. The researcher focused first on one student for five seconds and restarted the cycle after all students were observed. The on/off task student behaviors were recorded for all participants. These tallies indicate that on average, students were on task $71 \%$ of the time, and off task $29 \%$ of the time.

\section{Discussion, Conclusions, and Future Directions}

Teachers confront challenging behaviors on a daily basis (Reinke et al. 2014). First and most importantly, the teachers believed they set the tone for the classroom. Effective classroom managers understand that their reactions to classroom issues escalate or deescalate behaviors (Harrell et al. 2004; Hawkins et al. 1999; Oliver 2007). Unfortunately, effective strategies prove difficult to use at times. All teachers used non-verbal interventions whenever possible, as they were the least intrusive and most likely to deal with the issue at hand while preserving student dignity. At times, teachers used different hand signals to indicate disapproval, they tapped the desks or their students' shoulders to refocus their attention, they conducted instruction near their students, and they perfected their "teacher look." Other times, they used verbal interventions to redirect misbehaviors. Teachers found that some strategies, such as joking with the students, using attention getters and redirects, or name-dropping were very effective in addressing minor behaviors. Perhaps the most popular strategy was the touch-and-go, as the teachers understood the importance of not dwelling on misbehavior. The teachers quickly addressed the misbehavior and moved on, closing the door to a power struggle between the teacher and the student.

Lastly, another measure of effective management was the increase of acceptable behaviors and the decrease of misbehaviors. On average, students were off-task only $29 \%$ of the instructional time. They were on task $71 \%$ of the time. This confirms previous research findings in the study conducted by Godwin et al. 2016, who found that in well managed classrooms, students were on task $70.70 \%$ of the time in their first study, and $73.58 \%$ of 
the time in their second study. Similarly, Baker (2007) and Lee, Kelly and Nyre (1999) estimated that children spent between $10 \%-50 \%$ of the time engaged in off task behaviors. The students in this study fell in the middle of these statistics, being less off task (29\%) than students in previous findings $(50 \%)$.

In conclusion, the ways teachers react to misbehavior has a great impact on classroom morale, as it may escalate or deescalate behaviors. Ginott's (1972) quote captured beautifully the impact the teacher's reaction to students has on the classroom morale:

I've come to a frightening conclusion that I am the decisive element in the classroom. It's my personal approach that creates the climate. It's my daily mood that makes the weather. As a teacher, I possess a tremendous power to make a child's life miserable or joyous. I can be a tool of torture or an instrument of inspiration. I can humiliate or heal. In all situations, it is my response that decides whether a crisis will be escalated or de-escalated and a child humanized or dehumanized. (pp. 15-16)

When teachers use this power in a positive way, they foster environments conducive to learning, developing communities of learners. In the context of today's schools, the need for teachers to develop a culturally responsive classroom management mindset is more relevant than ever. The onus is on higher education institutions to help candidates understand that classroom management is not a toolbox, but rather a mindset. Teacher educators need to model it in their classrooms, by understanding that education centers around the needs of the students, and not vice versa. As such, classroom management becomes fluid and it is determined by the classroom dynamics and culture.

Future longitudinal studies could further contribute to the research in the field of culturally responsive classroom management. Such studies could capture, for example, the change (if any) in teachers' understanding of culturally responsive classroom management in their first 2-4 years of teaching, and whether this change determines their classroom interaction.

\section{References}

Axtell, R. E. (1997). Gestures: the do's and taboos of body language around the world. New York: John Wiley \& Sons.

Baker, R. S. (2007). Modeling and understanding students' off-task behavior in intelligent tutoring systems. Proceedings of ACM CHI 2007: Computer-Human Interaction: 1059-1068.

Boice, R. (1996). Classroom incivilities. Research in Higher Education, 37 (4), 453-486.

Brown, D. F. (2003). Urban teachers' use of culturally responsive management strategies. Theory into Practice, 42 (4), 277-282.

Donovan, S. M., \& Cross, C. T. (2002). Minority students in special and gifted education. Washington DC: National Academy Press.

Farah, E. (2017). Effective strategies of a behavior management plan. School of education student capstone projects. 24 . https://digitalcommons.hamline.edu/hse_cp/24

Florida Department of Education. n.d. School district data.

Retrieved from: http://www.fldoe.org/schools/k-12-public-schools/school-dis-data.stml

Freiberg, J. H., Huzinec, A. C., \& S. M. Templeton, S. M. (2009). Classroom management: a pathway to student achievement. A study of fourteen inner-city elementary schools. Elementary School Journal, 110, 63-80.

Galanti, G. A. (2008). Caring for patients from different cultures. Philadelphia: University of Pennsylvania Press.

Ginott, H. G. (1972). Teacher and child: a book for parents and teachers. New York: Macmillan.

Godwin, K. E., Almeda, M. V., \& Seltman, H., Kai, S., Skerbetz, M. D., Baker, R. S, \& Fisher, A. V. (2016). Off task behavior in elementary school children. Learning and Instruction, 44, 128-143.

Grinder, M. (2005). ENVoY: Your personal guide to classroom management. Battle Ground: Mitchell Grinder \& Associates.

Harrell, P., Leavell, A., van Tassell, F., \& McKee, K. (2004). No teacher left behind: results of a five-year study of teacher attrition. Action in Teacher Education, 26, 47-59.

Hawkins, J., Catalano, R. F., Kosterman, R., Abbott, R. D., \& Hill, K. G. (1999). Preventing adolescent healthrisk behaviors by strengthening protection during childhood. Archives of Pediatrics and Adolescent Medicine, $153,226-234$

Hertzog, H. S. (2002). When, how, and who do I ask for help? Novices' perceptions of problems and assistance. Teacher Education Quarterly, 29, 25-41.

Hollie, S. (2012). Culturally and linguistically responsive teaching and learning: Classroom practices for student success. Huntington Beach: Shell Education.

Ingersoll, R. M. (2002). High turnover plagues schools. USA Today, 13A.

Kowalski, R. M. (2003). Complaining, teasing, and other annoying behaviors. New Haven: Yale University Press.

Lee, S. W., Kelly, K. E., \& Nyre, J. E. (1999). Preliminary report on the relation of students' on-task behavior with completion of school work. Psychological Reports, 84 (1), 267 -272.

Levin, J. \& Nolan, J. F. (2014). Principles of classroom management: a professional decision-making model. 
Upper Saddle River: Pearson Education, Inc.

Lewis, T. J., Hudson, S., Richter, M., \& Johnson, N. (2004). Scientifically supported practices in emotional and behavioral disorders: a proposed approach and brief review of current practices. Behavioral Disorders, 29, 247259.

Meister, D. G., \& Melnic, S. A. (2003). National new teacher study: beginning teachers' concerns. Teaching and Teacher Education, 24 (4), 87-94.

Nasey, C. (2012). Teachers' use of classroom-based management strategies: A survey of New Zealand teachers. Retrieved from: https://mro.massey.ac.nz/bitstream/handle/10179/3483/01_front.pdf?sequence=2\&isAllowed=y

Oliver, R. M. (2007). Effective classroom management: teacher preparation and professional development. Retrieved from: https://files.Ethan.ed.gov/fulltext/ED543769.pdf

Pres, D. (2017). Why do teachers like giving students the stare down? Retrieved from: https://www.quora.com/Why-do-teachers-like-giving-students-the-stare-down

Rakes, L., \& Park, A. (2014). Developing relationships with difficult students. AMLE Magazine.

Reinke, W. M., Stormont, M., Herman, K. C., \& Newcomer, L. (2014). Using coaching to support teacher implementation of classroom-based interventions. Journal of Behavioral Education, 23 (1), 150-167.

Ripp, P. (2013). Common misbehaviors and how I work with them. Retrieved from: https://pernillesripp.com/2013/05/16/common-misbehaviors-and-how-i-work-with-them/

Skiba, R., Ormiston, H., Martinez, S., \& Cummings, J. (2016). Teaching the social curriculum: classroom management as behavioral instruction. Theory into Practice, 55, 120-128.

Sun, R. C. F., \& Shek D. T. L. (2012). Student classroom misbehavior: an exploratory study based on teachers' perceptions. The Scientific World Journal, 1-8

Teaching Tolerance. (2016). Reframing classroom management: A toolkit for educators. Retrieved from: http://www.tolerance.org/sites/default/files/TT_Reframing_Classroom_Managment_Han douts.pdf

The Center for Technology in Education. (n.d.). Characteristics of urban education. Retrieved from: http://cte.jhu.edu/urbaneducation/ses1_act2_pag1.shtml

Ullucci, K. (2009). This has to be family: humanizing classroom management in urban schools. Journal of Classroom Interaction, 44 (1), 13-28.

Weinstein, C., Curran, M., \& Tomlinson-Clarke, S. (2003). Culturally responsive classroom management: awareness into action. Theory into Practice, 42 (4), 269-276. 